\title{
Role of golimumab, a TNF-alpha inhibitor, in the treatment of the psoriatic arthritis
}

This article was published in the following Dove Press journal:

Clinical, Cosmetic and Investigational Dermatology

25 May 2010

Number of times this article has been viewed

\author{
Melissa A Michelon' \\ Alice B Gottlieb ${ }^{1,2}$ \\ 'Tufts University School of Medicine, \\ ${ }^{2}$ Department of Dermatology, Tufts \\ Medical Center, Boston, MA, USA
}

\begin{abstract}
Psoriatic arthritis (PsA) is an inflammatory arthritis that affects many psoriasis patients and can often have a debilitating disease progression. Golimumab is a new tumor necrosis factor (TNF) antagonist recently approved by the FDA for controlling signs and symptoms of psoriatic arthritis. In a Phase III clinical trial in patients with PsA, patients receiving golimumab showed significant improvement in the signs and symptoms of disease. It was usually well tolerated, but adverse events generally occurred more in patients receiving golimumab compared to placebo. Golimumab has also recently shown efficacy in slowing structural damage in PsA. This new biologic therapy provides physicians with another option in the treatment of this inflammatory arthritis while offering patients certain advantages over other TNF antagonists.
\end{abstract}

Keywords: golimumab, psoriatic arthritis, TNF-alpha inhibitor

\section{Introduction}

Psoriatic arthritis is a seronegative inflammatory arthritis that affects approximately $0.25 \%$ of the general population in the United States and approximately $14 \%$ of psoriasis patients according to one recent study, though reported numbers have reached over $40 \%{ }^{1-3}$ Psoriatic arthritis can often present a diagnostic challenge due to a wide range of clinical presentations, degrees of severity, and may be difficult to distinguish from other inflammatory arthritides. The disease progression of PsA is variable and patients often present only with skin involvement for years before developing any joint symptoms. The symptoms described by psoriatic arthritics may present as less severe relative to other inflammatory arthritis such as rheumatoid arthritis (RA), and may be deemed a milder form despite underlying structural damage. ${ }^{3}$ A complicated clinical picture and a paucity of symptoms may cause a delay in diagnosis and treatment which could then lead to a quiet progression of the structural damage.

Once diagnosed, appropriate treatment of PsA, based the severity of disease, should be initiated to improve the signs and symptoms and minimize the negative disease impact on patients' lives. For mild disease, this typically involves the use of nonsteroidal anti-inflammatory drugs (NSAIDs), physical therapy, and/or corticosteroid injections. For moderate to severe disease, more aggressive treatment is necessary in order to inhibit progression of structural damage. Disease-modifying antirheumatic drugs (DMARDs) are available, but their efficacy in PsA when used alone has not been well established. TNF blockade with or without methotrexate has been demonstrated to control signs and symptoms, inhibit X-ray progression and improve quality of life in patients with PsA. ${ }^{46}$
Correspondence: Alice Gottlieb, MD, PhD Tufts Medical Center, Department of Dermatology, 800 Washington Street, Box II4, Boston, MA 02III, USA

Tel + I 6176365370

Fax +l 6176369169

Email agottlieb@tuftsmedicalcenter.org 
There are a number of options for biologic treatments, particularly the TNF antagonists. Most show similar efficacy and side effect profiles. Golimumab, one of the newest TNF blockers, was recently shown to be efficacious in improving not only the signs and symptoms of PsA, but also in treating the structural damage caused by the disease making it a reasonable option in treating moderate to severe PsA.

\section{Mode of action}

Golimumab is one of the newer TNF antagonists to become available and is currently indicated for controlling the signs and symptoms of active PsA in adult patients. Manufactured by Centocor Ortho Biotech, Inc (Horsham, PA, USA) under the trade name Simponi, golimumab is a fully human antiTNF IgG monoclonal antibody with affinity for both soluble and transmembrane $\mathrm{TNF}^{7}$ It targets and neutralizes a key contributing factor in the inflammatory process as well as the pathophysiology of chronic inflammatory diseases, including RA, PsA, and ankylosing spondylitis (AS). ${ }^{8}$

\section{Pharmacokinetics}

Serum concentrations of golimumab were generally doseproportional in Phase III clinical trials, ${ }^{9,10}$ though Kay et al also reported a large variation between patients. ${ }^{11}$ Steady-state concentrations of golimumab were achieved by Week 12 in these trials. $^{9-11}$

$\mathrm{Xu}$ et al determined population pharmacokinetic parameters of golimumab based on data collected in the GO-REVEAL study of patients with PsA. ${ }^{9,12}$ Analysis of serum concentrations showed an apparent clearance of $1.38 \pm 0.04 \mathrm{~L} / \mathrm{d}$ and an apparent volume of distribution of $24.9 \pm 1.04 \mathrm{~L}$ for patients weighing a standard $70 \mathrm{~kg} .{ }^{12}$ The authors found that body weight was a significant covariate for both the apparent clearance and apparent volume of distribution. Patients receiving the $50 \mathrm{mg}$ dose of golimumab and with a body weight greater than $100 \mathrm{~kg}$ showed less improvement based on American College of Rheumatology (ACR) criteria than those patients weighing less than $100 \mathrm{~kg}$ receiving the same dose. This difference in response rates based on body weight was not as evident in the patients receiving the $100 \mathrm{mg}$ dose of golimumab, and the authors suggested that a dose adjustment may be necessary in patients weighing over $100 \mathrm{~kg} .{ }^{12}$ Other significant covariates found for the apparent clearance included antibodies to golimumab status, smoking status, and baseline C-reactive protein level. The use of concomitant medications, including NSAIDs, corticosteroids, and methotrexate, was also analyzed for potential effects. In the group receiving the $50 \mathrm{mg}$ golimumab dose, there appeared to be a reduction in clearance of golimumab with concomitant use of methotrexate, but this effect was not seen in the group receiving the $100 \mathrm{mg}$ dose of golimumab and overall was not significant. The authors also determined a half-life for golimumab of 12.5 days. ${ }^{12}$

\section{Efficacy}

In the Phase III clinical trial of golimumab in patients with active PsA, significant improvement in the signs and symptoms of the disease was shown following treatment with golimumab at doses of $50 \mathrm{mg}$ and $100 \mathrm{mg}$ every 4 weeks. ${ }^{9}$ Kavanaugh et al also found that $51 \%$ of patients treated with $50 \mathrm{mg}$ golimumab and $45 \%$ of patients treated with $100 \mathrm{mg}$ of golimumab achieved an American College of Rheumatology $20 \%$ improvement criteria (ACR20) response at week 14, the study's primary endpoint, compared to only $9 \%$ in patients receiving placebo ( $P<0.001$ for both comparisons). This efficacy of golimumab was maintained at week 24 of the trial where $52 \%$ of patients in the $50 \mathrm{mg}$ golimumab and $61 \%$ in the $100 \mathrm{mg}$ golimumab groups achieved an ACR20 response compared to only $12 \%$ in the placebo group $(P<0.001$ for both comparisons). ${ }^{9}$ This response is comparable to that observed with other TNF antagonists (see Table 1).

Approximately half of the patients in this trial were also taking stable doses of concomitant methotrexate. The proportion of patients on methotrexate and their mean dosages were similar in all treatment groups and the ACR20 response at week 14 was observed regardless of methotrexate use. ${ }^{9}$

Patients in this same study with at least 3\% body surface area (BSA) affected by psoriasis were also evaluated for changes in the Psoriasis Area and Severity Index (PASI) score. It was found that $40 \%$ of these patients in the $50 \mathrm{mg}$ golimumab group and 58\% in the $100 \mathrm{mg}$ golimumab group achieved a $75 \%$ improvement in their PASI score (PASI75) at week 14 compared to only $3 \%$ of patients receiving placebo ( $P<0.001$ for both comparisons). At week 24 , $56 \%$ of patients in the $50 \mathrm{mg}$ golimumab group and $66 \%$

Table I Efficacy comparison of golimumab (50 mg once monthly) and other TNF antagonists ${ }^{4-6,9}$

\begin{tabular}{lll}
\hline TNF antagonist & $\begin{array}{l}\text { ACR20 response at } \\
\text { week I2 or I4 }\end{array}$ & $\begin{array}{l}\text { PASI75 at } \\
\text { week 24 }\end{array}$ \\
\hline Etanercept & $59 \%$ & $23 \%$ \\
Adalimumab & $58 \%$ & $59 \%$ \\
Infliximab & $58 \%$ & $60 \%$ \\
Golimumab & $51 \%$ & $56 \%$ \\
\hline
\end{tabular}

${ }^{\mathrm{a} A C R 20}$ response observed at week 12 for etanercept and adalimumab, at week 14 for infliximab and golimumab. 
in the $100 \mathrm{mg}$ group achieved a PASI75 compared to $1 \%$ in the placebo group ( $P<0.001$ for both comparisons) (Table 1).

Changes in nail involvement were also assessed using the Nail Psoriasis Severity Index (NAPSI) and Physician's Global Assessment (PGA) of psoriatic nail disease. Patients treated with golimumab showed significant improvement in nail involvement compared to placebo at week 14 and at week $24 .{ }^{9}$

The proportion of patients with enthesitis in the $50 \mathrm{mg}$ and $100 \mathrm{mg}$ golimumab groups was $49 \%$ and $50 \%$, respectively, compared to $69 \%$ in the placebo group at week 24 ( $P=0.002$ and $P=0.003$, respective comparisons). Significant improvement in the PsA-modified Maastricht Ankylosing Spondylitis Enthesitis Score (MASES) was also observed. A $60 \%$ median change was observed in those receiving $50 \mathrm{mg}$ golimumab and $67 \%$ in those receiving $100 \mathrm{mg}$ golimumab compared to only a $12 \%$ median score change in those receiving placebo $(P<0.001$ for both). There was no significant difference observed in the proportion of patients with dactylitis through week 24 , though the severity of dactylitis had significantly improved in patients treated with $100 \mathrm{mg}$ of golimumab relative to placebo. ${ }^{9}$

Kavanaugh et al also showed that golimumab was efficacious in improving physical function and quality of life. They observed that patients treated with golimumab had significantly improved Health Assessment Questionnaire (HAQ) and Short-Form 36 (SF-36) scores at week 14 compared to placebo. ${ }^{9}$

Long-term efficacy of golimumab has been observed; with continued response rates through 2 years of treatment. ${ }^{13}$ The proportion of patients who remained on the $50 \mathrm{mg}$ dose of golimumab achieving an ACR20 response at weeks 52 and 104 were $78 \%$ and $91 \%$, respectively. Patients who remained on the $100 \mathrm{mg}$ dose also showed continued response at week 52 with $81 \%$ achieving an ACR20, though the proportion of patients with that response decreased to $73 \%$ at week 104 . In the $50 \mathrm{mg}$ group, $62 \%$ and $69 \%$ of patients achieved a PASI 75 at weeks 52 and 104, respectively. In the group treated with $100 \mathrm{mg}$ of golimumab, $70 \%$ and $76 \%$ of patients achieved a PASI75 at weeks 52 and 104, respectively. Improvement in HAQ scores was also maintained for both groups through week $104 .^{13}$

\section{Radiographic changes}

Additionally, golimumab has been shown to slow structural joint damage, specifically articular erosions and joint space narrowing, which has been observed radiographically.
Kavanaugh et al recently reported that PsA patients receiving golimumab showed significantly less progression of joint space disease at week 52 of treatment compared to those receiving placebo. ${ }^{14}$

\section{Safety and tolerability}

Golimumab was usually well tolerated in Phase III trials, but adverse events generally occurred more in patients receiving golimumab compared to placebo. Kavanaugh et al reported adverse events in $65 \%$ of all golimumab-treated patients compared to $59 \%$ of those receiving placebo, and serious adverse events in $2 \%$ and $6 \%$ of patients, respectively. ${ }^{9}$ Similarly, Inman et al reported $85.6 \%$ of patients treated with golimumab and $76.6 \%$ of patients receiving placebo reported at least one adverse event, whereas 5.4\% of the golimumab-treated patients reported at least 1 serious adverse event compared to $6.5 \%$ of patients receiving placebo. ${ }^{10}$

The side effect profile of golimumab is similar to that of other TNF antagonists. ${ }^{4-6}$

\section{Common adverse reactions}

Injection site reactions were among the common adverse reactions reported in Phase III clinical trials of golimumab. ${ }^{9-11,15-17}$ One trial reported injection site reactions at a rate of $8.7 \%$ in the $50 \mathrm{mg}$ golimumab group and $6.4 \%$ in the $100 \mathrm{mg}$ group compared to $2.6 \%$ in the placebo group. ${ }^{10}$ Kavanaugh et al reported that injection site reactions in the combined golimumab group (3\%) were comparable to the placebo group $(3 \%) .{ }^{9}$ The most common reaction was erythema, which was generally mild and did not lead to discontinuation of treatment. ${ }^{9,11,15-17}$ No anaphylactic reactions have been reported for golimumab in clinical trials. Other common adverse reactions in these trials included upper respiratory infections, nasopharyngitis, and headache. ${ }^{9,11,15,16}$ Similar common adverse events were observed in clinical trials of other TNF antagonists. ${ }^{4-6}$

\section{Infections}

In Phase III clinical trials, more subjects receiving golimumab developed any type of infection during the study periods compared to those receiving placebo ${ }^{9-11}$ or methotrexate alone. ${ }^{16}$ Though uncommon, serious infections, including sepsis and pneumonia, have been reported in patients taking golimumab similar to those taking other TNF antagonists. Kay et al reported 3 patients treated with golimumab who developed pneumonia, including 1 patient who also developed septic shock, and 1 patient in the placebo group developed a lower respiratory infection. ${ }^{11}$ Because 
infections can be serious, even fatal, ${ }^{16}$ golimumab should not be prescribed to patients with evidence of an active infection or are immunocompromised.

TNF is thought to play an important role in host defense against infection, particularly against intracellular bacteria, ${ }^{8}$ inferring a degree of susceptibility to these types of infections with the use of TNF antagonists. In Phase III trials of golimumab, anti-tuberculosis treatment was initiated prior to entering the study in patients who showed evidence of latent tuberculosis infection. ${ }^{9,10,16,17}$ One case of tuberculosis of the spine was reported in a patient receiving golimumab during these trials. ${ }^{17}$ The diagnosis had been made only after the patient's treatment with golimumab began, was based on the observation of caseating granulomas in a surgical specimen, and the diagnosis was not confirmed by any other method. No other cases of active or reactivation tuberculosis were reported in clinical trials. It is recommended that all patients be screened for evidence of latent infection and treated appropriately prior to initiation of treatment with golimumab.

\section{Abnormal laboratory values}

Elevations in liver enzymes were reported in trials of golimumab. More patients receiving golimumab had increased liver transaminases compared to placebo. Kavanaugh et al reported $24 \%$ of patients in the $50 \mathrm{mg}$ golimumab group, $35 \%$ in the $100 \mathrm{mg}$ golimumab group, and $18 \%$ in the placebo group had elevations in alanine aminotransferase (ALT) levels. Aspartate aminotransaminase (AST) was also elevated in $18 \%, 13 \%$, and $10 \%$ of patients, respectively. ${ }^{9}$ Patients were generally asymptomatic and most of these elevations were not serious. ${ }^{9,10}$ Many of the patients with increased AST and ALT levels were concurrently receiving other medications such as isoniazid for treatment of latent tuberculosis ${ }^{9,10}$ or methotrexate. ${ }^{10}$ However, Emery et al did not find an increased risk of serious AST or ALT elevations with concomitant use of golimumab and isoniazid. ${ }^{17}$

Two cases of anemia were reported in a Phase III clinical trial in patients receiving $100 \mathrm{mg}$ of golimumab plus placebo. $^{17}$

\section{Malignancy}

Patients treated with any of TNF antagonists, including golimumab, may be at higher risk for developing certain malignancies, including lymphoma, than the general population. It is not clear, however, if the presence of a chronic inflammatory disease, like rheumatoid arthritis, itself may predispose patients to developing lymphoma. ${ }^{18}$ Only solid malignancies were reported in one Phase III clinical trial, two cases of basal cell carcinoma and one case of prostate cancer in the group receiving a higher dose of golimumab (100 mg monthly) compared to no reports of malignancy in the lower golimumab dose (50 mg monthly) or placebo groups through week 24 of the study. ${ }^{9}$ Smolen et al reported a case of squamous cell carcinoma of the skin in a patient receiving $50 \mathrm{mg}$ golimumab, lymphoma in a patient receiving $100 \mathrm{mg}$ golimumab, and pancreatic cancer in a patient receiving placebo. ${ }^{15}$ Emery et al reported breast cancer and squamous cell carcinoma of the lip in patients receiving methotrexate plus placebo, another case of breast cancer in a patient receiving $50 \mathrm{mg}$ golimumab plus methotrexate, and Hodgkin's lymphoma in a patient receiving $100 \mathrm{mg}$ golimumab plus methotrexate. ${ }^{17}$ Keystone et al also reported four malignancies, two cases of non-melanoma skin cancer in patients receiving $100 \mathrm{mg}$ golimumab alone and one case of breast cancer in a patient receiving $100 \mathrm{mg}$ golimumab and methotrexate compared to 1 case of basal cell cancer in a patient taking methotrexate alone. ${ }^{16}$

\section{Congestive heart failure}

TNF antagonists, including golimumab, can potentially exacerbate CHF. ${ }^{19}$ In a Phase III clinical trial in patients with rheumatoid arthritis despite methotrexate treatment one patient reported congestive heart failure. ${ }^{11}$ New onset CHF has also been reported with other TNF antagonists. Care should be taken when prescribing golimumab in patients with CHF and they should be monitored routinely for signs and symptoms of deterioration of their condition or newly developing CHF.

\section{Autoimmunity}

The development of autoantibodies, particularly antinuclear and anti-dsDNA antibodies, is associated with the use of TNF antagonists. ${ }^{20}$ Inman et al reported $10.1 \%$ of patients receiving $50 \mathrm{mg}$ golimumab, $14.8 \%$ of those receiving $100 \mathrm{mg}$ golimumab, and $12.9 \%$ receiving placebo were newly positive for antinuclear antibodies, but only one of these patients developed anti-dsDNA antibodies. ${ }^{10}$ In another clinical trial, the rate of antinuclear antibodies in the golimumab plus methotrexate treated groups was $12.2 \%$ (combined) and was comparable to placebo plus methotrexate $(14.9 \%)$. The rate of antinuclear antibodies was found to be higher in the golimumab alone group (29.3\%). ${ }^{16}$ One case of systemic lupus erythematosus (SLE) was reported in Phase III clinical trials. The patient had tested positive for antinuclear antibodies prior to treatment initiation and developed SLE within days after receiving their first dose of golimumab. ${ }^{15}$ Currently, there 
are no recommendations for monitoring of autoantibodies in patients taking TNF antagonists. Antibodies to golimumab itself were found in $2.1 \%$ to $6.3 \%$ of golimumab-treated patients $^{9,16,17}$ in Phase III clinical trials, though none of the patients receiving methotrexate at baseline developed antibodies to the drug. ${ }^{9}$

\section{Warnings \\ Potential class effects}

Other TNF antagonists have been associated with additional adverse events that were not reported for golimumab in the above referenced Phase III clinical trials. Because of the potential for class effects, it is important to consider these additional risks when prescribing golimumab to patients. There are reports of new onset and exacerbation of the demyelinating disorders, including multiple sclerosis, in patients while taking TNF antagonists. ${ }^{21,22}$

Reactivation of hepatitis B virus has occurred in chronic carriers taking TNF antagonists and was even fatal in some cases, although most of these patients were also taking other immunosuppressive drugs. ${ }^{7}$ Chronic hepatitis $\mathrm{C}$ infection is not a contraindication to the use of TNF antagonists, but these patients should be closely monitored during treatment. ${ }^{23}$

There are also reports of other hematologic cytopenias in patients receiving other TNF antagonists, though often in combination with drugs that can suppress bone marrow function. The use of TNF antagonists may also exacerbate psoriasis in patients or cause new onset psoriasis.

\section{Interactions}

The manufacturer also recommends that golimumab not be prescribed if the patient is taking abatacept or anakinra, due to the increased risk of serious infections with concurrent use. ${ }^{7}$

\section{Use of golimumab in practice}

This new biologic therapy provides physicians with another option in the treatment of these often debilitating diseases and may offer certain advantages over other biologic therapies. Smolen et al showed that golimumab was effective at improving the signs and symptoms of active rheumatoid arthritis in patients who had previously discontinued other TNF antagonists mainly for lack of effectiveness, intolerance, or inaccessibility. The authors suggest that golimumab is a possible alternative therapy when other TNF antagonists are not tolerated. ${ }^{15}$

Another advantage of golimumab over other TNF antagonists is that its dosing schedule may offer more convenience to the patient. It is dosed once monthly as a subcutaneous injection that can be self-administered at home. ${ }^{7}$ This schedule is compared to that of other TNF blockers, including intravenous infusions of infliximab every 4 to 8 weeks, weekly subcutaneous dosing of etanercept, and every other week subcutaneous dosing of adalimumab for treatment of the same indications..$^{24-26}$

\section{Conclusion}

Golimumab, one of the newest TNF antagonists to reach the market, is an appealing treatment option for patients with moderate to severe psoriatic arthritis. Its once monthly home dosing may be attractive to some patients. Golimumab may also be an effective alternative when patients fail treatment with other TNF antagonists.

\section{Disclosures}

Melissa Michelon has no disclosures. Nearly all of Dr Gottlieb's income is paid directly to her employer. Dr Gottlieb currently has consulting/advisory board agreements with the following: Amgen Inc, Centocor Inc, Wyeth Pharmaceuticals, Celgene Corp, Bristol-Myers Squibb Co, Beiersdorf Inc, Abbott Labs, Roche, Sankyo, TEVA, Actelion, UCB, Novo Nordisk, Immune Control, DermiPsor, Incyte, Corgentech, PureTech, Magen Biosciences, Cytokine Pharmasciences, Inc, Ono, CanFite, Pfizer, Schering-Plough and Alnylam. Dr Gottlieb is the Principal Investigator for research/educational grants paid to Tufts Medical Center from Centocor, Amgen, Wyeth, Immune Control, Celgene, Incyte, Abbott, Pfizer, and Novo Nordisk.

\section{References}

1. Gelfand JM, Gladman DD, Mease PJ, et al. Epidemiology of psoriatic arthritis in the population of the United States. J Am Acad Dermatol. 2005;53:573-577.

2. Ibrahim G, Waxman R, Helliwell PS. The prevalence of psoriatic arthritis in people with psoriasis. Arthritis Rheum. 2009;61(10):1373-1378.

3. Gottlieb A, Korman NJ, Gordon KB, et al. Guidelines of care for the management of psoriasis and psoriatic arthritis, Section 2. Psoriatic arthritis: overview and guidelines of care for treatment with an emphasis on the biologics. J Amer Acad Dermatol. 2008;58:851-864.

4. Antoni C, Krueger GG, de Vlam K, et al. Infliximab improves signs and symptoms of psoriatic arthritis: results of the IMPACT 2 Trial. Ann Rheum Dis. 2005;64:1150-1157.

5. Mease PJ, Kivitz AJ, Burch FX, et al. Etanercept treatment of psoriatic arthritis: safety, efficacy, and effect on disease progression. Arthritis Rheum. 2004;50(7):2264-2272.

6. Mease PJ, Gladman DD, Ritchlin CT, et al. Adalimumab for the treatment of patients with moderately to severely active psoriatic arthritis: results of a double-lind, randomized, placebo-controlled trial. Arthritis Rheum. 2005;52(10):3279-3289.

7. Centocor Inc. Simponi (golimumab): Product insert (US) [online]. From Drugs@FDA. Accessed Apr 26 2010. URL: http://www.accessdata.fda. gov/drugsatfda_docs/label/2009/125289s000lbl.pdf

8. Tracey D, Klareskog L, Sasso E, Salfeld J, Tak P. Tumor necrosis factor antagonist mechanism of action: a comprehensive review. Pharmacol Ther. 2008;117:244-279. 
9. Kavanaugh A, McInnes I, Mease P, et al. Golimumab, a new human tumor necrosis factor $\alpha$ antibody, administered every four weeks as a subcutaneous injection in psoriatic arthritis. Arthritis Rheum. 2009;60(4):976-986.

10. Inman R, Davis JC, van der Heijde D, et al. Efficacy and safety of golimumab in patients with ankylosing spondylitis. Arthritis Rheum. 2008;58(11):3402-3412.

11. Kay J, Matteson EJ, Dasgupta B, et al. Golimumab in patients with active rheumatoid arthritis despite treatment with methotrexate. Arthritis Rheum. 2008;58(4):964-975.

12. Xu Z, Vu T, Lee H, et al. Population pharmacokinetics of golimumab, an anti-tumor necrosis factor- $\alpha$ human monoclonal antibody, in patients with psoriatic arthritis. J Clin Pharmacol. 2009;49:1056-1070.

13. Kavanaugh A, Mease P, Krueger GG, et al. Golimumab, a new human, TNF alpha antibody, administered subcutaneously every 4 weeks in psoriatic arthritis patients: 104-week efficacy and safety results of the randomized, placebo-controlled GO-REVEAL study. Abstract presented at the 2009 European League Against Rheumatism (EULAR) Annual Congress. Jun 10-13: Copenhagen.

14. Kavanaugh A, van der Heijde D, Gladman D, et al. Golimumab inhibits progression of radiographic damage in patients with psoriatic arthritis: 52 week results From the GO-REVEAL study. Abstract presented at the 2009 ACR/ARHP Annual Scientific Meeting. Oct 17-21: Philadelphia.

15. Smolen JS, Kay J, Doyle MK, et al. Golimumab in patients with active rheumatoid arthritis after treatment with tumour necrosis factor $\alpha$ inhibitors (GO-AFTER study): a multicentre, randomized, double-blind, placebo-controlled, phase III trial. Lancet. 2009;374:210-221.

16. Keystone EC, Genovese MC, Klareskog L, et al. Golimumab, a human antibody to tumor necrosis factor given by monthly subcutaneous injections, in active rheumatoid arthritis despite methotrexate therapy: the GO-FORWARD Study. Ann Rheum Dis. 2009:68:789-796.
17. Emery P, Fleischmann RM, Moreland LW, et al. Golimumab, a human anti-tumor necrosis factor $\alpha$ monoclonal antibody, injected subcutaneously every four weeks in methotrexate-naïve patients with active rheumatoid arthritis. Arthritis Rheum. 2009;60(8):2272-2283.

18. Baecklund E, Iliadou A, Askling J, et al. Association of chronic inflammation, not its treatment, with increased lymphoma risk in rheumatoid arthritis. Arthritis Rheum. 2006;54(3):692-701.

19. Chung E, Packer M, Lo KH, Fasanmade AA, Willerson JT. Randomized, double-blind, placebo-controlled, pilot trial of infliximab, a chimeric monoclonal antibody to tumor necrosis factor-a, in patients with moderate-to-severe heart failure. Circulation. 2009; 107:3133-3140.

20. Kerbleski JF, Gottlieb AB. Dermatological complications and safety of anti-TNF treatments. Gut. 2009;58(8):1033-1039.

21. The Lenercept Multiple Sclerosis Study Group and The University of British Columbia MS/MRI Analysis Group. TNF neutralization in MS: results of a randomized, placebo-controlled multicenter study. Neurology. 1999;53(3):457-465.

22. Sicotte NL, Voskuhl RR. Onset of multiple sclerosis associated with anti-TNF therapy. Neurology. 2001;57:1885-1888.

23. Frankel AJ, Van Voorhees AS, Hsu S, Korman NJ, Lebwohl MG, Bebo BF, et al; for the National Psoriasis Foundation. Treatment of psoriasis in patients with hepatitis $\mathrm{C}$ : from the Medical Board of the National Psoriasis Foundation. J Amer Acad Dermatol. 2009. In press.

24. Centocor, Inc. Remicade ${ }^{\circledR}$ (infliximab): Product insert (US) [online]. From Drugs@FDA. Accessed Apr 26, 2010. URL: http://www. accessdata.fda.gov/drugsatfda_docs/label/2009/103772s5234lbl.pdf

25. Immunex Corporation. Enbrel ${ }^{\circledR}$ (etanercept): Product insert (US) [online]. From Drugs @FDA. Accessed Apr 26, 2010. URL: http://www. accessdata.fda.gov/drugsatfda_docs/label/2008/103795s5359lbl.pdf

26. Abbott Laboratories. Humira ${ }^{\circledR}$ (adalimumab): Product insert (US) [online].From Drugs@FDA. Accessed Apr 26, 2010. URL: http://www. accessdata.fda.gov/drugsatfda_docs/label/2008/125057s114lbl.pdf
Clinical, Cosmetic and Investigational Dermatology

\section{Publish your work in this journal}

Clinical, Cosmetic and Investigational Dermatology is an international, peer-reviewed, open access, online journal that focuses on the latest clinical and experimental research in all aspects of skin disease and cosmetic interventions. All areas of dermatology will be covered; contributions will be welcomed from all clinicians and

\section{Dovepress}

basic science researchers globally. This journal is indexed on CAS The manuscript management system is completely online and includes a very quick and fair peer-review system, which is all easy to use. Visit http://www.dovepress.com/testimonials.php to read real quotes from published authors. 